\title{
PRODUÇÃO CIENTíFICA E TECNOLÓGICA NO BRASIL: CONQUISTAS RECENTES E DESAFIOS PARA A PRÓXIMA DÉCADA
}

\author{
Sergio Machado Rezende \\ Professor do Centro de Ciências Exatas e da Natureza, Universidade Federal de Pernambuco - Recife - PE, Brasil \\ rezende@df.ufpe.br
}

O Plano de Ação em Ciência, Tecnologia e Inovação para o Desenvolvimento Nacional (PACTI), implantado entre 2007-2010, conseguiu apresentar resultados muito satisfatórios. Diferentemente de projetos anteriores, mais do que um conjunto de intenções, realizou-se um plano concreto com ações, prioridades claras, institucionalidade, programas, metas e orçamento. O plano do Ministério da Ciência e Tecnologia (MCT) articulou diferentes áreas do Governo Federal com os Estados da Federação e as principais entidades e associações científicas e empresariais do País, mobilizando um total de R\$ 41,2 bilhões.

Quatro prioridades estratégicas da Política Nacional de Ciência, Tecnologia e Inovação ( $C, T \& I$ ) nortearam a execução desse plano: Expansão e Consolidação do Sistema Nacional de Ciência, Tecnologia e Inovação; Promoção da Inovação Tecnológica nas Empresas; Pesquisa, Desenvolvimento e Inovação em Áreas Estratégicas; e Ciência, Tecnologia e Inovação para o Desenvolvimento Social.

\section{CONSOLIDAÇÃO DO SISTEMA NACIONAL DE CIÊNCIA, TECNOLOGIA E INOVAÇÃO}

Com base no relatório Principais Resultados e Avanços, divulgado pelo MCT em dezembro de 2010, os principais resultados do PACTI foram: (1) forte aumento da articulação entre Governo Federal, Estados e associações científicas, contribuindo para consolidar o Sistema Nacional de C,T\&I; (2) ampliação das ações e iniciativas de cooperação internacional em Ciência e Tecnologia (C\&T); (3) aumento considerável no número de bolsas de estudo e de pesquisa do Conselho Nacional de Desenvolvimento Científico e Tecnológico (CNPq) e da Coordenação de Aperfeiçoamento de Pessoal de Nível Superior (CAPES); (4) forte ampliação dos recursos e das modalidades de financiamento da pesquisa científica e tecnológica; (5) conclusão da conexão à Internet em alta velocidade de todas as universidades, escolas técnicas e instituições de pesquisa do País através da Nova Rede Nacional de Pesquisa (RNP). A seguir, o detalhamento desses resultados.

A articulação e as parcerias do MCT e de suas agências com os Estados ocorreram por meio das Secretarias de Ciência e Tecnologia e Fundações de Amparo à Pesquisa (FAPs), através de acordos de cooperação técnico-científica, fortalecimento do Programa de Apoio a Núcleos de Excelência (PRONEX), e pelo lançamento do Programa Institutos Nacionais de Ciência e Tecnologia (INCTs). Este último contou com o edital de maior volume de recursos federais disponibilizados até hoje para esse tipo de parceria, $\mathrm{R} \$$ 609 milhões.

Entre 2007 e 2010, um grande avanço no marco legal contribuiu para a consolidação do Sistema Nacional de C,T\&I. Forte articulação entre o Governo Federal e os Governos Estaduais promoveu leis, decretos e portarias, não apenas em nível federal mas também nos Estados. Até julho de 2010, 14 Estados já haviam sancionado leis de inovação, 2 possuíam projeto de lei em tramitação e 3 outros já tinham minuta de 
lei em análise nos seus respectivos legislativos.

Para facilitar a interação entre os diversos segmentos que compõem o Sistema Nacional de C,T\&I, o MCT manteve intensa articulação com a Academia Brasileira de Ciências $(A B C)$, a Sociedade Brasileira para o Progresso da Ciência (SBPC), a Associação Nacional dos Dirigentes das Instituições Federais de Ensino Superior (ANDIFES), o Conselho Nacional de Secretários Estaduais para Assuntos de C,T\&I (CONSECTI), o Conselho Nacional das Fundações de Amparo à Pesquisa (CONFAP), o Fórum dos Secretários Municipais de Ciência e Tecnologia, a Confederação Nacional da Indústria (CNI) e diversas Associações Empresariais Setoriais.

No âmbito do Governo Federal, o objetivo foi articular o plano executado pelo MCT com a Política de Desenvolvimento Produtivo (PDP), o Plano de Desenvolvimento da Educação (PDE), a Política de Desenvolvimento da Agropecuária (PDA), o Programa Mais Saúde e a Política Nacional de Defesa. Destaca-se, também, a revitalização do Conselho Nacional de Ciência e Tecnologia (CCT), que contribuiu para manter o diálogo entre diversos atores no nível federal em posição estratégica.

No que se refere à cooperação internacional, o Brasil tem tomado iniciativas relevantes e atendido às demandas cada vez mais intensas nas atividades, hoje estratégicas, de cooperação internacional em ciência, tecnologia e inovação em diversas áreas do conhecimento. Fortaleceram-se os laços da colaboração Sul-Sul, em especial com Mercosul, América do Sul e América Latina. Foram ampliados os contatos e programas no âmbito da cooperação América do Sul-Países Árabes (ASPA) e com países africanos, em particular com a Co- munidade de Países de Língua Portuguesa, especialmente na formação de recursos humanos e cooperação na construção de infraestrutura de pesquisa. O Fórum IBAS e as relações com seus países (Índia, Brasil e África do Sul) avançaram consideravelmente, com a diversificação dos programas de trabalho. A cooperação com a China, além do bem-sucedido programa espacial, mobiliza novas áreas. Intensificou-se o trabalho conjunto com os países desenvolvidos, com destaque para Alemanha, França, União Europeia, Estados Unidos, Reino Unido, Finlândia, Suíça, além de muitos outros, em programas essenciais de mútuo interesse.

O grande aumento nos recursos financeiros federais disponíveis para $C, T \& I$ permitiu alavancar recursos dos governos estaduais, ampliando a formação de recursos humanos e o financiamento adequado da pesquisa básica e aplicada em todas as áreas do conhecimento e em todos os níveis da estrutura do Sistema Nacional de C,T\&I. Foi considerável o aumento do número de bolsas do CNPq e da CAPES para estudantes, desde a iniciação científica até a pós-graduação. O número de bolsas das duas agências evoluiu de 77.579 em 2001 para 149.579 em 2009, e os recursos disponibilizados passaram de $\mathrm{R} \$ 813$ milhões para $\mathrm{R} \$ 2$ bilhões no mesmo período. Ainda assim, temos cerca de 8 pesquisadores por $10 \mathrm{mil}$ habitantes, um terço do encontrado em países industrializados.

Para ampliar os recursos e as modalidades de financiamento à pesquisa, o CNPq dispõe, atualmente, de editais em programas que apoiam diversos tipos de projetos. O Edital Universal, substancialmente ampliado com recursos provenientes do Fundo Nacional de Desenvolvimento Científico e Tecnológico (FNDCT), apoia projetos de pesquisa de indiví- duos e grupos, para o qual podem ser apresentadas propostas em qualquer área do conhecimento. Entre 2007 e 2009 , esses editais selecionaram mais de 11 mil projetos, totalizando mais de R $\$ 500$ milhões.

Dois outros programas foram criados recentemente pelo CNPq especificamente voltados a jovens pesquisadores, dando a eles oportunidade de obter financiamento sem concorrer diretamente com pesquisadores mais experientes: o Programa Jovens Pesquisadores e o Programa Primeiros Projetos. Ambos visam estimular pesquisadores jovens e a nucleação de novos grupos, em quaisquer áreas do conhecimento, por meio de convênios firmados com entidades estaduais de fomento à pesquisa.

Para a realização de eventos, intercâmbio de pesquisadores em programas de cooperação internacional e divulgação e melhoria do ensino de Ciências, entre 2007 e 2010 o CNPq lançou 198 editais, disponibilizando $\mathrm{R} \$ 2,53$ bilhões, tendo sido selecionadas mais de 35 mil propostas. Criado na década de 1990, o PRONEX foi revigorado e ampliado pelo $\mathrm{CNPq}$ e, em 2008, passou a contar com recursos do FNDCT e a ser executado em parceria com FAPs estaduais. Há, atualmente, 250 Núcleos de Excelência financiados em 15 Estados, com recursos aprovados que totalizam $\mathrm{R} \$$ 162,7 milhões.

Em 2008, os INCTs substituíram os Institutos do Milênio, no maior programa da história do $\mathrm{CNPq}$, com o objetivo de congregar os melhores grupos de pesquisa em áreas de fronteira da ciência e em áreas estratégicas para o desenvolvimento do País, contribuindo para tornar a pesquisa científica e tecnológica brasileira mais competitiva internacionalmente (Gráfico 1). O programa é cofinanciado por: Financiadora de Estudos e Projetos (FINEP), Ministério da 
Saúde, CAPES, Banco Nacional de Desenvolvimento Econômico e Social (BNDES), Petrobras e Fundações Estaduais de Amparo à Pesquisa de SP, RJ, MG, SC, PA, AM, PI e RN. Os 122 INCTs selecionados no primeiro edital receberão, durante três anos, um total de $\mathrm{R} \$ 609$ milhões.

Enquanto o CNPq concede recursos a indivíduos, com compromissos firmados por meio de termos de concessão, a FINEP financia projetos de pesquisa e de infraestrutura com recursos do FNDCT. No período 20072009, a FINEP lançou 64 editais do FNDCT/Fundos Setoriais, tendo contratado, até o momento, 1.011 projetos com recursos que totalizam $\mathrm{R} \$ 1,82$ bilhão. Dentre os editais, destacam-se aqueles que fazem parte do Programa de Modernização da Infraestrutura (PROINFRA) das Instituições Científicas e Tecnológicas (ICTs), financiado com recursos do CT-Infra. Os recursos disponibilizados para apoio à infraes- trutura de pesquisa cresceram mais de 600\% entre 2003 e 2009.

Outro resultado importante do PACTI diz respeito à implantação da Nova Rede Nacional de Ensino e Pesquisa (RNP). A primeira rede de acesso à Internet no Brasil, implantada no início da década de 1990, oferecia, em 2004, a taxa máxima de transmissão de $622 \mathrm{Mbps}$. Atualmente, com taxa máxima em $10 \mathrm{Gbps}$, são possíveis aplicações inovadoras em áreas como educação (Universidade Aberta do Brasil e educação a distância), saúde (Rede Universitária de Telemedicina - RUTE) e cultura (TVs Universitárias, por exemplo). O aumento da velocidade no backbone da RNP foi acompanhado da implantação de redes metropolitanas de fibra óptica, chamadas Redecomep. Já existem 21 cidades com redes metropolitanas conectadas à RNP, interligando cerca de 600 entidades de ensino e pesquisa à Internet.

\section{PRODUÇÃO CIENTÍFICA E TECNOLÓGICA NO SETOR PRIVADO}

A consolidação e expansão da infraestrutura de C,T\&I influíram diretamente no volume da produção científica realizada no Brasil. Em 2009, o País já respondia por $2,69 \%$ da produção científica mundial, o dobro da participação existente em 2000. Desde então, o número de publicações aumentou 205\%, atingindo 32.100 artigos indexados na base de dados National Science Indicators (NSI), editada pela Thomson Reuters Scientific. Em 2008, o País alcançou a $13^{a}$ colocação no ranking mundial da produção científica, ultrapassando Rússia e Holanda, países com grande tradição em Ciência. O ritmo de crescimento da produção científica brasileira tem se mostrado bem mais elevado do que aquele da produção mundial, como mostra o Gráfico 2. Enfim, pode-se

\section{Gráfico 1 - Evolução dos recursos de programas de apoio à pesquisa em todas as áreas do conhecimento}

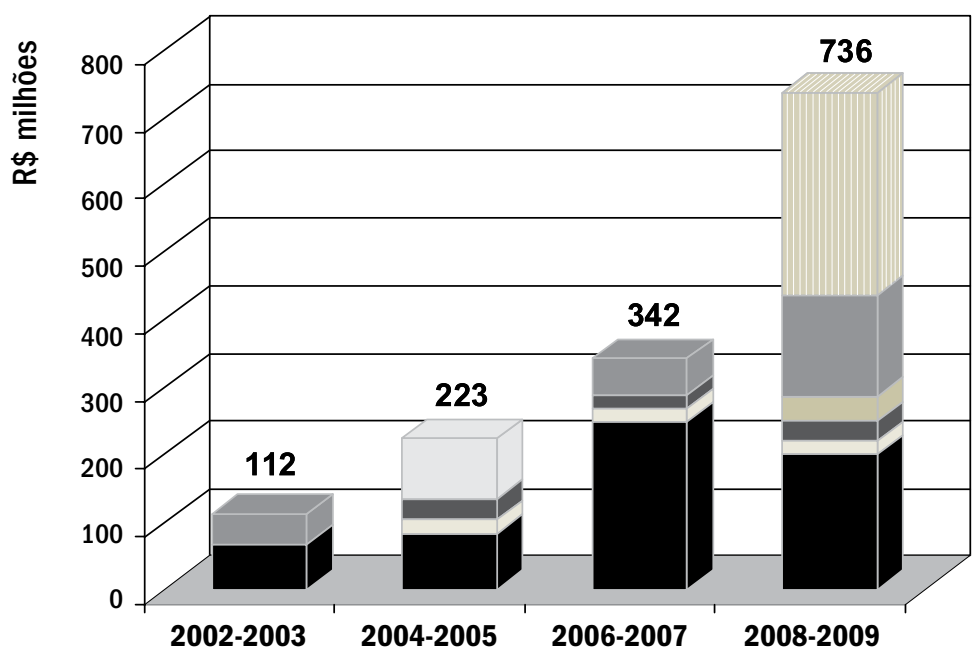

(1) somente recursos MCT
Ano de lançamento do edital
Pronex (1)

INCT (1)

Institutos do Milênio

Jovens Pesquisadores

Casadinho

Primeiros Projetos

Edital Universal

Fonte: Dados secundários do CNPq. 
constatar que, apesar do início tardio na formação de mestres e doutores, o País avançou muito em seu sistema de C\&T. Nossa produção científica cresce, há três décadas, mais que a do restante do mundo. O número de artigos publicados em revistas indexadas, que em 1981 era de $0,44 \%$ do total do mundo, em 2009 atingiu 2,7\%.

A inovação tecnológica nas empresas brasileiras, no entanto, ainda é tímida. Segundo a Pesquisa Industrial de Inovação Tecnológica (PINTEC) do Instituto Brasileiro de Geografia e Estatística (IBGE) de 2008, das 70 mil empresas industriais existentes em 2005 , somente $3 \%$ tinham introduzido um produto novo no mercado. Menos de $5 \%$ dos pesquisadores brasileiros atuam em empresas. Essa situação decorre da falta de cultura de inovação no ambiente empresarial e também da pouca articulação das políticas industriais e de C\&T.

A Promoção da Inovação Tecnológica nas Empresas constituiu um dos grandes desafios do PACTI. A inova- ção nas empresas passou a ser a principal prioridade comum da PDP e do PACTI. Por outro lado, as entidades empresariais, federações de indústria, associações setoriais e o Serviço Brasileiro de Apoio às Micro e Pequenas Empresas (SEBRAE) abraçaram a causa de colocar a inovação na agenda das empresas nacionais e têm liderado iniciativas importantes nessa direção. É importante destacar, também, a interação do PACTI com o Programa de Pesquisa e Desenvolvimento (P\&D) da Petrobras e com os programas de apoio à inovação do BNDES, mediante os instrumentos da PDP.

Um amplo leque de instrumentos de financiamento de projetos empresariais foi criado para impulsionar o ambiente de inovação tecnológica no setor privado do País. Esses instrumentos são operados pela FINEP e pelo BNDES, por incentivos fiscais, criação do Sistema Brasileiro de Tecnologia (SIBRATEC) e mobilização de empresas e entidades empresariais.

Até 2005, o principal instrumento para apoiar inovação nas empresas era a linha de crédito da FINEP com Taxa de Juros de Longo Prazo (TJLP) mais $5 \%$. Hoje, surge um novo cenário para a inovação no País, permitindo às empresas a utilização de um leque de instrumentos bem mais amplo e efetivo e estimulando a criação de novas empresas baseadas em tecnologia.

O Programa Primeira Empresa Inovadora (PRIME), que entrou em operação no início de 2009, concede subvenção econômica para start-ups (empresas jovens com potencial de criação e desenvolvimento de conceitos). A operacionalização do PRIME é feita em parceria com 17 incubadoras de empresas pré-selecionadas, e já apoia 1.381 empresas escolhidas por meio de editais regionais. Cada empresa recebeu, em 2009, R\$ $120 \mathrm{mil}$ de subvenção, totalizando um aporte de R 166 milhões. Essas empresas poderão, no segundo ano, receber mais $\mathrm{R} \$ 120$ mil em recursos reembolsáveis com juros subsidiados do Programa Juro Zero. E, muito impor-

Gráfico 2 - Crescimento relativo da produção científica no Brasil e no mundo, com referência a 1982

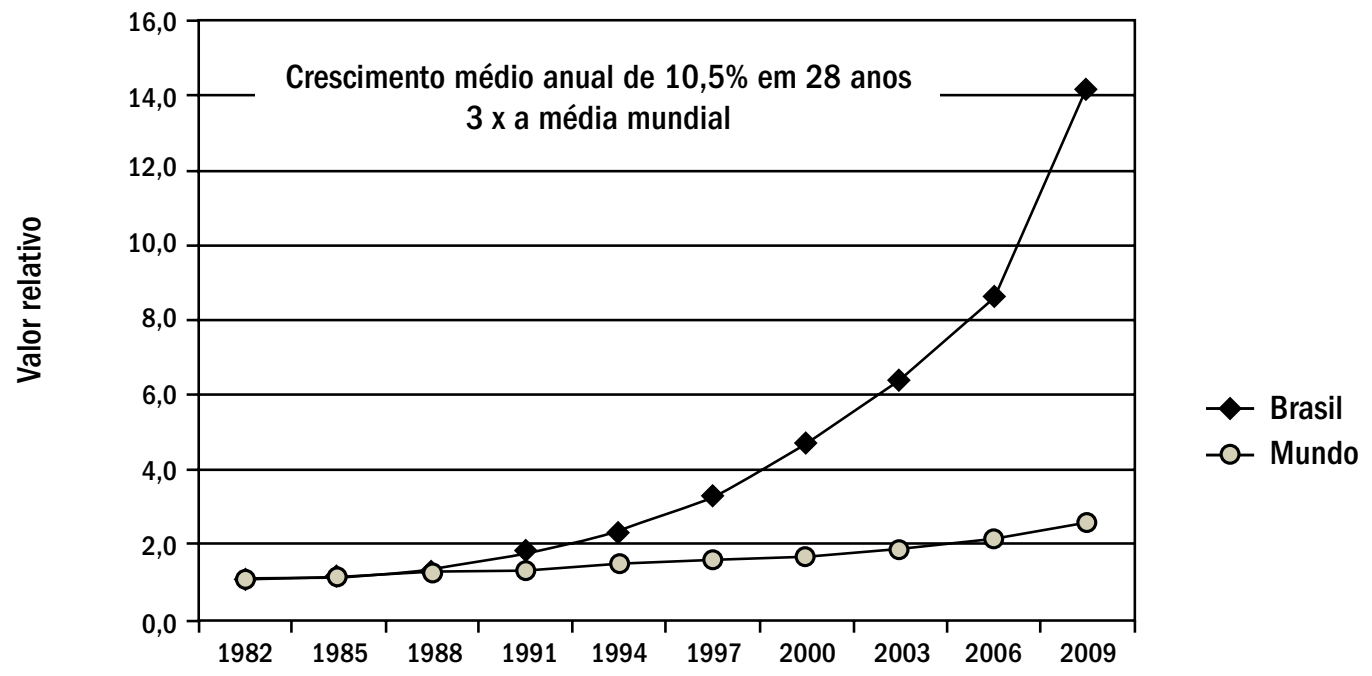

Fonte: Base de dados NSI, editada pela Thomson Reuters Scientific INC, 2009; dados secundários da CAPES. 
tante, existem hoje mais de 30 fundos de capital de risco, criados com apoio da FINEP e do BNDES, com mais de $\mathrm{R} \$ 3$ bilhões para investir nas novas empresas inovadoras.

A Lei de Inovação de 2004 viabilizou a subvenção econômica administrada pela FINEP com recursos não reembolsáveis de cerca de $\mathrm{R} \$ 2$ bilhões para empresas inovadoras por meio de três programas: Edital Nacional da FINEP, Programa de Apoio à Pesquisa na Pequena Empresa (PAPPE) e PRI$\mathrm{ME}$, os dois últimos em parceria com os Estados.

Os Editais Nacionais de Subvenção passaram a ser anunciados anualmente a partir de 2006 e, desde então, um total de R \$ 1,566 milhões de recursos não reembolsáveis foram aportados para 825 projetos de empresas, selecionados entre 8.890 propostas. Os editais focaram em diferentes áreas tecnológicas, sendo priorizados os setores mais diretamente vinculados com a PDP: biotecnologia, nanotecnologia, tecnologias da informação e de comunicação (TICs), TV digital, fármacos e medicamentos, energias renováveis e aeroespacial. A partir de 2007, a área de desenvolvimento social, que antes estava inserida na parcela de "temas gerais", ganhou destaque específico.

O PAPPE, em parceria com as FAPs, prevê o aporte de recursos financeiros a pequenas e médias empresas para o fomento de atividades de inovação em setores importantes para o desenvolvimento local. Quatorze Estados lançaram editais para contratação de projetos, tendo selecionado mais de 400 empresas. Os investimentos nessa modalidade de subvenção chegaram a $\mathrm{R} \$ 265$ milhões, sendo $\mathrm{R} \$ 150$ milhões do FNDCT e R 115 milhões de contrapartida de FAPs, SEBRAE e Federações da Indústria. Por esse programa, empresas com faturamento de até $\mathrm{R} \$ 10,5$ milhões ao ano podem receber financiamentos entre $R \$ 200$ mil e R\$ 400 mil.

Além das operações não reembolsáveis, a FINEP apoia a inovação nas empresas também com duas operações reembolsáveis: o Inova Brasil e o Juro Zero. Substituindo o antigo Pró-Inovação, o Inova Brasil (Programa de Incentivo à Inovação nas Empresas Brasileiras) constitui-se em financiamento com encargos reduzidos para a realização de projetos de pesquisa, desenvolvimento e inovação nas empresas brasileiras, como suporte à PDP. Desde 2007, já foram apoiados 166 projetos, com recursos que totalizam $\mathrm{R} \$ 2,8$ bilhões, passando de $\mathrm{R} \$ 557,8$ milhões em 2007 para $\mathrm{R} \$$ 1,7 bilhão em 2009. O Programa Juro Zero é uma modalidade de financiamento para apoio a projetos ou planos de negócios desenvolvidos por micro e pequenas empresas inovadoras, em um período máximo de 18 meses, e que representem inovação de processo, de produto ou de serviço em seu setor. Foram apoiados 47 projetos de empresas, desde 2007, com recursos de R \$ 36,7 milhões.

De janeiro de 2007 a agosto de 2010, o desembolso do BNDES por meio das linhas de financiamento, dos programas de apoio à inovação e do crédito à aquisição de bens de capital de micro e pequenas empresas já totalizou R\$ 5,2 bilhões. Entre 2007 e 2009 , esse desembolso cresceu na ordem de $36 \%$. A carteira atual de operações nas linhas e programas de apoio à inovação apresenta um montante de R \$ 7,3 bilhões, incluindo-se nesse grupo as operações ativas contratadas - saldo a desembolsar, aprovadas, em análise, enquadradas, com consulta e em perspectiva.

A Lei do Bem, de 2005, beneficia com incentivos fiscais empresas que declararem investimento em pesquisa e inovação. Em 2006, 130 empresas declararam investimentos de aproximadamente $\mathrm{R} \$ 2,2$ bilhões em pesquisa. Em 2008, o número de empresas inovadoras saltou para 460 e os investimentos privados em pesquisa e inovação atingiram $\mathrm{R} \$ 8,8$ bilhões. Com isso, o investimento em $P \& D$ do setor privado evoluiu de 0,09\% para $0,28 \%$ do Produto Interno Bruto (PIB) em apenas três anos.

O Programa Nacional de Apoio às Incubadoras de Empresas e Parques Tecnológicos (PNI), criado em 2004, é outra importante iniciativa para a promoção do desenvolvimento tecnológico e da inovação nas micro e pequenas empresas. Em 2009, cerca de 8 mil empresas inovadoras, instaladas em 400 incubadoras de empresas localizadas em todo o País, geraram 35 mil empregos, com faturamento total de cerca de R $\$ 3,5$ bilhões. Os parques tecnológicos promovem desenvolvimento econômico e tecnológico ao fomentar sinergias nas atividades de pesquisa e inovação entre as empresas e instituições científicas, públicas e privadas. Com forte apoio institucional e financeiro dos Governos Federal, Estadual e Municipal, comunidade local e setor privado, até 2009 havia 74 iniciativas de parques tecnológicos no País (25 em operação, 17 em implantação e 32 em projeto).

O Programa RHAE-Pesquisador na Empresa do CNPq provê bolsas para pesquisadores, mestres e doutores, que atuam nas empresas. Em 2008, 131 empresas foram contempladas, possibilitando a inserção de 195 mestres e doutores, além de 180 técnicos, para composição da equipe de trabalho. Com o acréscimo dos recursos no programa, em 2009, as 172 empresas selecionadas absorveram 312 mestres e doutores e 378 técnicos. De 2008 a 2010 , os recursos destinados ao programa foram da ordem de $\mathrm{R} \$ 76$ milhões.

O mais recente estímulo para inovação nas empresas vem da Medida Provisória $n^{\circ} 495 / 2010$, que deu ori- 
gem à Lei $\mathrm{n}^{\circ} 12.349$, aprovada pelo Congresso no dia 15 de dezembro de 2010. Ela altera a Lei $n^{\circ} 8.666$, que regulamenta as licitações públicas no País. Os novos dispositivos abrem a possibilidade de conceder margem de preferência nas licitações estatais às empresas brasileiras, especialmente às empresas que investem em pesquisa e desenvolvimento no País, em até $25 \%$. Esse instrumento é considerado central no desenvolvimento produtivo e tecnológico de setores como saúde, TICs, defesa e aeronáutico. A Lei $\mathrm{n}^{\circ}$ 12.349 representa o alcance de uma das metas do PACTI e da PDP para possibilitar ao Estado a utilização de seu poder de compra para impulsionar o desenvolvimento de produtos e processos nas empresas brasileiras.

Para fomentar a imprescindível interação universidade-empresa, o Governo Federal implantou o Sistema Brasileiro de Tecnologia (SIBRATEC). Ele é formado por 56 redes de grupos e núcleos de P\&D articuladas nacionalmente, sendo 14 redes de centros de inovação, 20 de serviços tecnológicos, e 22 de extensão, estas organizadas estadualmente. O SIBRATEC é coordenado pelo MCT, mas tem a participação ativa de vários ministérios e entidades federais, como FINEP, BNDES e Instituto Nacional de Metrologia, Normalização e Qualidade Industrial (INMETRO). As redes de extensão têm a missão primordial de apoiar a inovação nas micro e pequenas empresas e, por isso mesmo, têm uma articulação crescente com o SEBRAE. As redes de serviços tecnológicos fazem com que a metrologia de qualidade e laboratórios de análise de conformidade de produtos e processos dê suporte à produção no complexo campo das disputas comerciais.

A projeção internacional do Brasil em C\&T, somada ao nosso desenvolvimento econômico acelerado, tem contribuído para atrair a instalação de centros de P\&D de empresas multinacionais no País. Somente em 2010, anunciaram suas decisões de instalar no Brasil centros mundiais de pesquisa as americanas General Electric e IBM e a sueca SAAB.

Ainda há um longo caminho a ser percorrido, porém, é certo que passos importantes têm sido dados, e existem sinais claros da incorporação gradativa do conceito de inovação no nosso setor empresarial. Enfim, a inovação tecnológica entrou definitivamente na agenda do setor privado nacional e, certamente, contribuirá para tornar as empresas brasileiras mais competitivas, lucrativas e em condições de conquistar novos mercados. Finalmente, o Brasil começa a formar uma geração de empresários inovadores.

\section{ÁREAS ESTRATÉGICAS}

Outra prioridade do PACTI foi o desenvolvimento de 13 áreas estratégicas: áreas portadoras de futuro: Biotecnologia e Nanotecnologia; Tecnologias da Informação e Comunicação; Insumos para a Saúde; Biocombustíveis; Energia Elétrica, Hidrogênio e Energias Renováveis; Petróleo, Gás e Carvão Mineral; Agronegócio; Biodiversidade e Recursos Naturais; Amazônia e Semi-Árido; Meteorologia e Mudanças Climáticas; Programa Espacial; Programa Nuclear; e Defesa Nacional e Segurança Pública. Com seus 59 programas, essas áreas representaram $68 \%$ das atividades do PACTI, e receberam, no período 2007 2009, recursos financeiros do MCT de cerca de $\mathrm{R} \$ 3$ bilhões.

Os resultados desses programas são bastante amplos e variados, indicando que todas essas áreas estratégicas tiveram seu desenvolvimento acelerado em razão do PACTI. Quero destacar, aqui, apenas resultados em três áreas que considero muito rele- vantes: microeletrônica, biocombustíveis e clima.

A microeletrônica, estratégica por sua transversalidade em todos os setores industriais, havia sido praticamente abandonada nas políticas de C\&T e industrial da década de 1990. O Programa Nacional de Microeletrônica, implantado em 2003, está formando centenas de projetistas de circuitos integrados em dois centros de treinamento e 18 centros de design houses em todo o País. A empresa Centro Nacional de Tecnologia Eletrônica Avançada S.A (CEITEC), vinculada ao MCT, foi implantada em Porto Alegre com investimentos do MCT de cerca de R 500 milhões, para construção, aquisição e instalação de equipamentos para um Centro de Projetos e uma fábrica de circuitos integrados, a primeira da América do Sul.

Os avanços na microeletrônica no Brasil nos últimos anos trazem uma satisfação pessoal, pois se trata de uma área que acompanho de perto há várias décadas. Por isso, reproduzo aqui um trecho do artigo que escrevi a respeito do cinquentenário da descoberta do transistor:

Entretanto, como construímos uma base de C\&T considerável, certamente a maior e melhor da América Latina, talvez possamos comemorar o $70^{\circ}$ aniversário do transistor. Para isso será preciso elaborar um plano industrial para o setor de eletrônica e informática, com a participação equilibrada de empresas estrangeiras e nacionais, e com ingredientes semelhantes aos dos planos dos países asiáticos. Ele deverá aproveitar a experiência de inúmeros parques tecnológicos e incubadoras existentes no país, e conter um forte programa de $C \& T$ e de intercâmbio com o exterior. Os instrumentos necessários já existem e estão no BNDES, FINEP e CNPq. Os atores estão nas universidades, nos centros de pesquisa e no setor empresarial. $\mathrm{O}$ 
mais difícil, sem dúvida, será executar o plano com determinação, perseverança e muito trabalho, durante vinte anos! (REZENDE, 1997)

$\mathrm{Na}$ área de biocombustíveis, merecem destaque a implantação da Rede de Bioetanol e a criação do Centro de Ciência e Tecnologia do Bioetanol (CTBE), instalado no campus do Centro Nacional de Pesquisa em Energia e Materiais. Com o objetivo de contribuir para a manutenção da liderança brasileira na produção sustentável de bioetanol da cana-de-açúcar, o CTBE recebeu investimentos de cerca de $\mathrm{R} \$$ 100 milhões e está realizando pesquisas com foco nos entraves agrícolas e tecnológicos dessa cadeia produtiva, como mecanização de baixo impacto para o plantio direto de cana-de-açúcar (com vistas à preservação do solo e à redução de custos no plantio e na colheita), e hidrólise enzimática da biomassa lignocelulósica, além de modelagem, a exemplo da biorrefinaria virtual, e de estudos sobre sustentabilidade da produção de bioetanol.

Destaco, também, a criação da Rede Clima (Rede Brasileira de Pesquisa sobre Mudanças Climáticas), instituída pelo MCT em 2007, com o objetivo de gerar e disseminar conhecimento e tecnologia para que o Brasil possa responder às demandas e desafios representados pelas causas e efeitos das mudanças climáticas globais e embasar políticas brasileiras de prevenção, adaptação e mitigação. De abrangência nacional, a Rede Clima envolve dezenas de grupos de pesquisa em universidades e institutos, com foco científico em todas as questões relevantes das mudanças climáticas: agricultura, biodiversidade, desastres naturais, energias renováveis, megacidades, políticas públicas, recursos hídricos, saúde humana e zonas costeiras. O MCT está investindo R \$ 30 milhões em três anos para a implantação da Rede Clima, além de ter contribuído com $\mathrm{R} \$ 35$ milhões, em conjunto com a Fundação de Amparo à Pesquisa do Estado de São Paulo (FAPESP), para aquisição de um supercomputador para o Instituto Nacional de Pesquisas Espaciais (INPE), o qual estará operando no início do próximo ano. O novo supercomputador ampliará em mais de 50 vezes a capacidade de processamento no INPE e será fundamental para o desenvolvimento e a implementação do Modelo Brasileiro do Sistema Climático Global. Estão sendo investidos também $\mathrm{R} \$$ 7,2 milhões no INCT para Mudanças Climáticas, o qual reúne cerca de 400 pesquisadores, estudantes e técnicos, de 76 grupos de pesquisa brasileiros e 19 estrangeiros.

\section{DESENVOLVIMENTO SOCIAL E POPULARIZAÇÃO DA CIÊNCIA}

Para o desenvolvimento social, com foco no ensino e na popularização da Ciência, os principais destaques do PACTI são a Semana Nacional de Ciência e Tecnologia e a Olimpíada Brasileira de Matemática das Escolas Públicas (OBMEP). A Semana Nacional de Ciência e Tecnologia, realizada desde 2004, é a principal iniciativa de popularização da Ciência e tem contado com mobilização crescente em todo o País. Durante a Semana, em geral a segunda ou terceira do mês de outubro a cada ano, entidades de ensino e/ou pesquisa promovem atividades de divulgação da Ciência, em suas instalações ou em espaços públicos. Em 2009, a Semana envolveu 472 Municípios e contou com cerca de 25 mil atividades, com a participação de um público estimado em 12 milhões de estudantes.

Outro programa que chama a atenção pelo êxito alcançado é a OBMEP, a principal ação para a melhoria do ensino de Ciências. A tradicional Olim- píada de Matemática, realizada desde a década de 1970, tinha participação insignificante de alunos de escolas públicas, pois estes "não tinham coragem de enfrentar os alunos mais bem preparados das escolas privadas"como disse a Professora Suely Druck ao Presidente Lula em 2004. A OBMEP foi criada em 2005 para atender à demanda do Presidente e, naquele ano, teve a participação de cerca de 10 milhões de estudantes. Em 2010, a OBMEP teve quase 19,7 milhões de alunos inscritos, vindos de 44.717 escolas de 99,4\% dos Municípios brasileiros. A OBMEP tornou-se um grande programa mobilizador do ensino de Matemática e está tendo grande impacto na melhoria do ensino de Ciências nas escolas públicas.

\section{METAS PARA 2022, ANO DO BICENTENÁRIO}

A ampliação dos recursos federais para C,T\&I, associada aos inúmeros programas articulados com os Estados, estimula e viabiliza o aumento gradativo dos investimentos estaduais. O dispêndio nacional em $P \& D$, somados os investimentos públicos federal e estaduais com os das empresas privadas, apresenta crescimento contínuo, demonstrando sua importância relativa na economia brasileira. Os dispêndios em $\mathrm{P} \& \mathrm{D}$ em relação ao PIB, que historicamente no Brasil foram inferiores ou da ordem de $1 \%$, em 2007 foram de 1,07\% estimam que tenham alcançado $1,3 \%$ a $1,35 \%$ em 2010. Essa taxa é inferior à meta de 1,5\% do PIB prevista em 2007 por inúmeras razões. Uma delas é que ela foi concebida com base em valores do PIB divulgados à época, os quais eram menores do que os revisados posteriormente pelo IBGE. A outra foi a expansão aquém do previsto nos investimentos das empresas privadas. 
O sucesso obtido na execução do PACTI indica o acerto no processo de sua formulação e na escolha das prioridades estratégicas, linhas de ação e programas. A execução do plano de maneira articulada, com antigos e novos parceiros do Sistema, resultou na construção de um arco de alianças que fortaleceu a posição central que $C, T \& I$ devem ocupar no processo de desenvolvimento do País. O papel exercido pelo MCT na liderança e coordenação do plano contribuiu para que o Ministério fosse alçado a um novo patamar de importância política no Governo Federal e, em consequência, para o aumento substancial de seu orçamento.

A aceleração no desenvolvimento científico e no processo de assimilação da necessidade em promover a inovação tecnológica nas empresas contribuiu para aumentar a percepção da sociedade brasileira do fato que C,T\&I são, no cenário mundial contemporâneo, componentes essenciais para o desenvolvimento, o crescimento econômico, a geração de emprego e renda e a democratização de oportunidades. O trabalho de cientistas, engenheiros e de técnicos e o engajamento das empresas são fatores determinantes para a consolidação de um modelo de desenvolvimento sustentável, capaz de atender às justas demandas sociais dos brasileiros e ao permanente fortalecimento da soberania nacional. Essa é uma questão de Estado, que ultrapassa os governos.

Nas três últimas décadas, a economia mundial tem passado por um período de intensa dinâmica tecnológica e de forte aumento da concorrência. O progresso técnico e a competição internacional implicam que, sem investimentos em $C, T \& I$, um país dificilmente alcançará o desenvolvimento virtuoso, no qual a competitividade não dependa da exploração predatória de recursos naturais ou humanos. É preciso continuar a investir na formação de recursos humanos de alto nível e na acumulação de capital intangível: a incorporação de conhecimento na sociedade brasileira.

Novos desafios se apresentam neste momento de revisão e aperfeiçoamento da política de C,T\&I. Em primeiro lugar, é imperativo fazer com que $\mathrm{C}, \mathrm{T} \& \mathrm{I}$ se tornem efetivos componentes do desenvolvimento sustentável, do ponto de vista econômico e socioambiental. Em segundo lugar, é indispensável que as ações em C,T\&I sejam tomadas como Política de Estado, com a ampliação dos investimentos no setor, o aumento no número de instituições de pesquisa e de pesquisadores, com o aperfeiçoamento do marco legal existente, criando um ambiente favorável à inovação, e com o aumento na celeridade e melhoria dos processos de gestão.

Soma-se a isso a necessidade de intensificar as ações e iniciativas de C,T\&I para o grande público; melhorar a educação em todos os níveis e, em particular, o ensino de Ciências nas escolas, a fim de identificar e atrair talentos que demonstrem potencial para se desenvolver como inventores, cientistas, pesquisadores e empreendedores; e expandir com qualidade a distribuição geográfica da Ciência.

Por fim, é necessário aproveitar as vantagens comparativas do País para se manter à frente da discussão sobre o desenvolvimento sustentável e contribuir para que o Brasil se torne uma potência nesse novo paradigma, o que inclui, entre outras iniciativas, o uso sustentável, a conservação e a repartição de benefícios de nossa imensa biodiversidade.

Com base nas propostas da $4^{a}$ Conferência Nacional de C,T\&I, e levando em conta a evolução dos indicadores recentes de C,T\&I no Brasil, o
MCT propôs à Secretaria de Assuntos Estratégicos o seguinte conjunto de metas para 2022, ano em que o País estará celebrando o $200^{\circ}$ aniversário de sua independência:

- Ampliar os investimentos em P\&D para $2 \%$ do PIB, sendo mais da metade oriundo das empresas;

- Dobrar o número de bolsas/ano concedidas pelo CNPq e pela CAPES, passando dos atuais $170 \mathrm{mil}$ para 340 mil;

- Ter 450 mil pesquisadores, o que significará 2 pesquisadores por 1.000 habitantes, número que se aproxima da média dos países desenvolvidos;

- Alcançar 5\% da produção científica mundial;

- Triplicar o percentual de egressos dos cursos de nível superior em engenharia dos atuais 5\% para $15 \%$;

- Dominar as tecnologias de microeletrônica, de produção de fármacos, de nanotecnologia, de biotecnologia e de um conjunto de tecnologias verdes;

- Decuplicar o número de empresas inovadoras, passar dos 3\% das empresas industriais para 30\%;

- Decuplicar o número de patentes/ ano, passando do número atual de 400 para pelo menos 4.000;

- Assegurar independência na produção do combustível nuclear e nas tecnologias de reatores;

- Dominar as tecnologias de fabricação de satélites e de veículos lançadores.

Mantido o conjunto de fatores que caracterizam o cenário atual do País, as metas acima propostas são coerentes, factíveis e sinalizam a possibilidade concreta de se alcançar um novo padrão de desenvolvimento na próxima década, tendo C,T\&I como elementos essenciais para o desenvolvimento sustentável do Brasil. 